\title{
Retraction notice to: "Effect of grain orientation on friction and wear behavior of AZ91 magnesium alloy" [Lett. Mater. 11(2) (2021) 135-139]
}

\author{
M. Kumar \\ Department of Physics, Faculty of Science, Shree Guru Gobind Singh Tricentenary University Gurgaon, \\ Delhi-NCR, 122001, India
}

The paper has been retracted by the decision of the Editorial office. The author agrees to this retraction.

The author plagiarized part of the following paper: D. Kumar, N. N. Gosvami, J. Jain. Influence of crystallographic orientation on nanoscale friction and wear mechanisms of the AZ91 alloy. Tribology Letters. 2020. V. 68, Art. 89, https://doi.org/10.1007/s11249-020-01330-9. By manuscript submission, authors of Letters on Materials confirm that the reported results have been obtained in accordance with publication ethics. The Editorial office offers an apology to the readers that the fact of plagiarism was not detected in the submission and reviewing processes. 